\title{
Comparison of PIXE and XRF in the analysis of silver denarii of the early Piast
}

\author{
Janusz Lekki ${ }^{1}$ (D) Marta Matosz ${ }^{2} \cdot$ Czesława Paluszkiewicz $^{1} \cdot$ Ewa Pięta $^{1}$. \\ Tomasz Pieprzyca $^{1}$ - Zbigniew Szklarz ${ }^{1} \cdot J$ Julio M. del Hoyo Meléndez ${ }^{2}$
}

Received: 8 September 2017 / Published online: 20 October 2017

(c) The Author(s) 2017. This article is an open access publication

\begin{abstract}
The collection of denarii from the time of development of a Polish medieval state was studied using the proton induced X-ray emission spectroscopy. The major elements detected for these denarii are $\mathrm{Ag}$ and $\mathrm{Cu}$, while minor elements such as $\mathrm{Pb}, \mathrm{Fe}, \mathrm{Au}, \mathrm{Bi}$, and $\mathrm{Zn}$ may also be present. The aim of the study was to cross-compare the results with a previous micro-X-ray fluorescence data and to perform a better quantification of the denarii elemental composition, especially for trace elements, providing suggestions of the origin of alloy compounds.
\end{abstract}

Keywords Micro-PIXE · Micro-XRF · Silver denarii · Quantitative elemental composition · Medieval Poland . Numismatic collections

\section{Introduction}

Little information is available about the chemical composition of the oldest Polish denarii. The period concerned includes the reign of the three first Polish rulers: Mieszko I (ruled 962-992), Boleslaus the Brave (992-1025) and Mieszko II Lambert (1025-1031). The collection housed at

Electronic supplementary material The online version of this article (doi:10.1007/s10967-017-5556-8) contains supplementary material, which is available to authorized users.

Janusz Lekki

Janusz.Lekki@ifj.edu.pl

1 Institute of Nuclear Physics, Polish Academy of Sciences PAS, Radzikowskiego 152, 31-342 Cracow, Poland

2 Laboratory of Analysis and Non-Destructive Investigation of Heritage Objects, The National Museum in Krakow, 31109 Cracow, Poland the National Museum in Cracow consists of 71 items, minted in the period of about 995 to 1020 . The coins were made of a $\mathrm{Ag}-\mathrm{Cu}$ alloy, with addition of several less abundant elements with $\mathrm{Pb}$ being the most significant.

In a previous study del Hoyo-Melendez and co-workers (2015) examined this collection using micro-X-ray fluorescence (XRF) spectrometry and multiple conclusions have been drawn, mostly based on the quantitative analysis of major elements. The current study deals with the use of particle induced X-ray emission (PIXE) spectroscopy to perform a cross-comparison of the results obtained with both analytical techniques. In addition, better quantification of trace elements is possible through the use of these two complementary techniques. The information concerning elemental content is interesting since it may provide evidence about the alloys, the metal sources, and the technological processes employed to produce the denarii. The main objective of the study was to provide analytical data that may serve to enhance the existing knowledge about the beginnings of the Polish state.

\section{Experimental}

\section{Denarii}

A collection of $71 \mathrm{Ag}$ denarii minted between 995 and 1020 AD, from the Numismatic Cabinet of the National Museum in Cracow was investigated. The evaluated objects are divided into two broad categories: Boleslaus the Brave and Mieszko II Lambert. A full historical and archaeological description of the denarii can be found elsewhere [1, 2]. An example of one of the evaluated denarii, namely Boleslaus Type XI.17 is presented in 


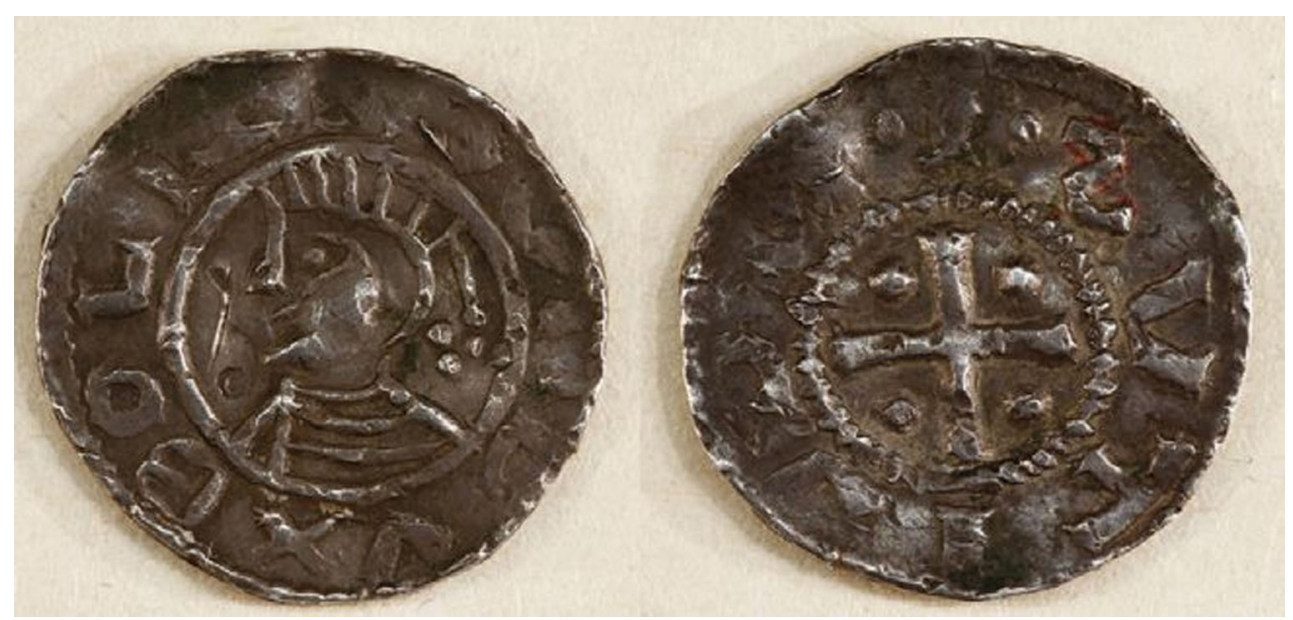

Fig. 1 Obverse and reverse of the Boleslaus the Brave denar (image: Piotr Frączek)

Fig. 1. Images on the left and right hand side correspond to obverse and reverse, respectively.

The physical characteristics of the denarii are as follows: weight: $0.5-3.0 \mathrm{~g}$, thickness: $0.5-1.0 \mathrm{~mm}$, diameter: 16-25 mm. Their size and good state of preservation make them ideal for investigations involving ion beam analytical techniques.

\section{Micro-X-ray fluorescence (XRF) spectrometry}

Micro-XRF analyses were carried out using a Bruker (Karlsruhe, Germany) Artax 400 XRF spectrometer equipped with a $\mathrm{Rh}$ tube and a collimator capable of producing an analytical spot of about $0.650 \mathrm{~mm}$. Bright and flat areas of the denarii were analyzed to avoid zones showing signs of corrosion and minimizing surface effects, respectively. The $\mathrm{X}$-ray generator was operated at $50 \mathrm{kV}$ and $0.5 \mathrm{~mA}$, while the acquisition time was $300 \mathrm{~s}$. This instrument has a Si drift X-ray detector with an active area of $10 \mathrm{~mm}^{2}$. The beam was focused on the analysis spot with the help of a laser and a camera, which are attached to the spectrometer. This instrument allows to perform nondestructive and non-contact measurements, while providing simultaneous multi-elemental analysis in the range from $\mathrm{Na}$ to $\mathrm{U}$. The average relative error estimated after evaluating a series of $\mathrm{Ag}-\mathrm{Cu}-\mathrm{Pb}$ standards was $\mathrm{Ag} \sim 2 \%$, $\mathrm{Cu} \sim 11 \%$, and $\sim 14 \%$ for $\mathrm{Pb}$. Acquisition and evaluation of XRF spectra was carried out using Spectra 5.3 (Bruker AXS Microanalysis, Berlin, Germany). The methodology has been described elsewhere [3, 4].

\section{PIXE-technique and experimental details}

The surface composition of the denarii was determined by means of micro-proton-induced X-ray emission ( $\mu \mathrm{PIXE}$ ), using the proton microprobe facility at the HVEC
K-3000 Van de Graaff accelerator of the Institute of Nuclear Physics (INP) in Cracow. For measurements, samples were placed in the experimental chamber (vacuum $\sim 10^{-5} \mathrm{hPa}$ ) and positioned in the microprobe focus using an on-line microscope for accurate selection of the investigated area. Additional details about the microprobe experimental setup have been described elsewhere [5].

The beam energy was $2.05 \mathrm{MeV}$ and the beam current intensity was in the range of $\sim 200$ to $300 \mathrm{pA}$. Rectangular areas $\left(256 \times 256 \mu^{2}, 128 \times 128\right.$ pixels $)$ were scanned with a proton beam of $\sim 20 \mu \mathrm{m}$ in diameter. Due to the non-homogeneous surface characteristics of the denarii, scanning mode was applied, however mostly not to obtain elemental area maps, but to collect more reliable data averaged from larger areas.

Samples of the studied material were deposited on a surface of a conducting carbon adhesive tape and next fixed to a sample holder and placed in the vacuum experimental chamber. To minimize the surface geometry effects, the beam spot position was always selected to cover a relatively flat area. The exact knowledge of the bombarding beam current was gained in the procedure following the basic idea presented in [6], where, during the measurement, the beam was periodically deflected and directed to a Faraday cup with a current integrator, monitored by the data acquisition system of the microprobe. For typical scanning experiments, such arrangement enables a line by line normalization of the X-ray data ( $\mu$ PIXE map), but in our case it served only to determine the number of protons bombarding the sample (target charge). X-ray and proton backscattering spectra were collected in the event-by-event mode using the multiparameter data acquisition system of the microprobe. The typical collection time was less than 10 min, corresponding to a total beam charge of at least $\sim 0.1 \mu \mathrm{C}$. The induced $\mathrm{X}$-rays were registered by the Princeton Gamma Tech $\mathrm{Si}(\mathrm{Li})$ detector characterized by a 
resolution of $160 \mathrm{eV}$ for the energy of $5.9 \mathrm{keV}$ and an active area of $80 \mathrm{~mm}^{2}$. The detector was placed $25 \mathrm{~mm}$ from the irradiated sample and a $260 \mu \mathrm{m}$ Kapton attenuation filter was placed between the detector and the sample. Data collection and processing was carried out using the INP microprobe proprietary software, interacting with two parallel systems: a digital and an analog one. The latter is based on the CAMAC system, while the former employs a $\mathrm{XiA}$ XMAP digital signal processor. The X-ray spectra collected by both systems were quantified using the GUPIX software package [7]. It is worth to mention that the outputs produced by both systems were close, but the digital one was delivering better performance and more reliable results. The GUPIX code provided a realistic estimation of errors, including the statistical part and the error related to the physical model and curve fitting. The typical relative error for matrix elements found in the studied denarii were as follows: $\mathrm{Ag}(\mathrm{K} \alpha$ line $)<1 \%, \mathrm{Cu} \quad(\mathrm{K} \alpha)<1 \%, \mathrm{~Pb}$ $(\mathrm{K} \alpha)<1 \%$.

In both techniques, XRF and PIXE, the time of single measurement was less than $10 \mathrm{~min}$. Due to differences in cross sections for $\mathrm{X}$-ray production and the intensity of the bombarding flux, the XRF spectra were up to one magnitude higher. However, due to specificity of the method, only PIXE enables reliable quantification of less abundant elements, including trace elements. The theoretical detection limit of the PIXE method extends to single ppm. In the current study, trace elements were reliably quantified to concentration levels of few hundreds of ppm.

\section{Results and discussion}

The following Fig. 2 shows variations in the aerial intensity of the characteristic X-ray signal, due to local contamination, inhomogeneity of the alloy (element segregation in silver-copper alloys), and surface corrosion.
These factors force the requirement of multiple measurements of every single denar.

As a reasonable compromise between accuracy and measurement time, typically three measurements of the obverse and three of the reverse were performed. To obtain a better estimation of the possible consequences of this compromise, several denarii were measured in 12 areas (instead of a standard number of 6). Figure 3 shows the results of these extra measurements on two denarii, illustrating limts of reproducibility of single measurements.

In these 12-elements sets, the standard deviation of a single measurement was approximately $2-3 \%$ for $\mathrm{Ag}$, $15-17 \%$ for $\mathrm{Cu}, 11-21 \%$ for $\mathrm{Pb}, 7-12 \%$ for $\mathrm{Au}$, and $30 \%$ for $\mathrm{Zn}$. Major elements results are in reasonable agreement with the standard deviation of previous $\mu \mathrm{XRF}$ measurements [3]. These results show that also in the case of less abundant major elements, like $\mathrm{Cu}$ and $\mathrm{Pb}$, extreme results of a single measurement of the same denar may differ by a factor of two. For even less abundant elements, like e.g. $\mathrm{Zn}$, such effect is even more severe. This observation, together with data delivered by aerial elemental maps, sets the reliability limit for the analysis and discussion of the results. The very limiting factor, particularly significant in the case of PIXE, is the limited depth (or volume) from where a useful X-ray signal may be detected. Due to contamination effects on the denarii surface and silver enrichment of the upper denar layer [8,9], it is usually difficult to reach the bulk of the studied object. The following Fig. 4 illustrates the fraction of the total X-ray signal registered in the detector versus the depth of the $\mathrm{X}$ ray origin, computed for an example, perfect coin, assumed to contain $95 \% \mathrm{Ag}$ and $5 \% \mathrm{Cu}$ (stoichiometry). Stopping powers for $2.05 \mathrm{MeV}$ protons penetrating the target have been calculated using the SRIM package [10], while the Xray production data were delivered by the GUCSA code, being a part of the GUPIX software [7].
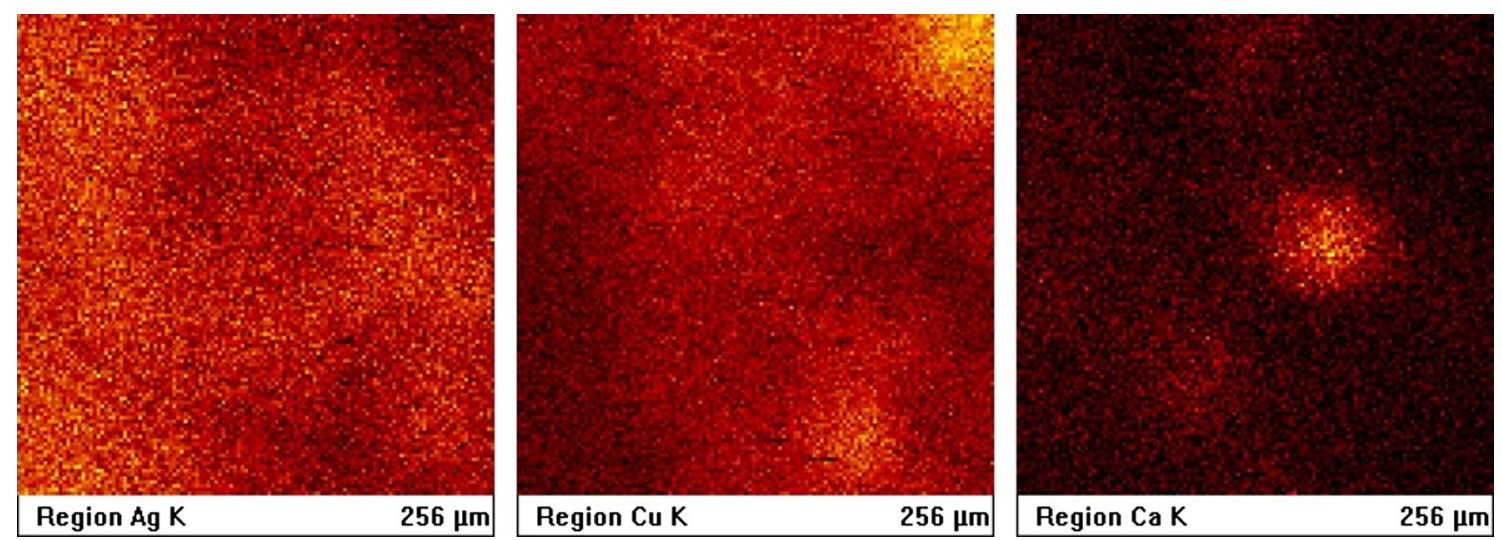

Fig. 2 PIXE elemental maps obtained for major elements $\mathrm{Ag}$ and $\mathrm{Cu}$, proving a non-uniform distribution of the X-ray signal from the denarius surface. The third map most probably shows an example of surface contamination with $\mathrm{Ca}$ 


\section{$\mathrm{Ag}(\%)$}

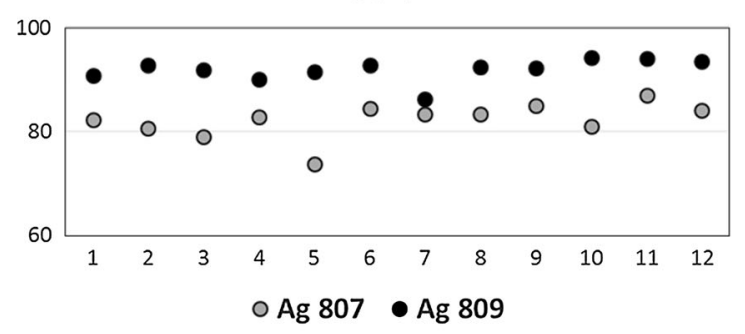

$\mathrm{Cu}(\%)$

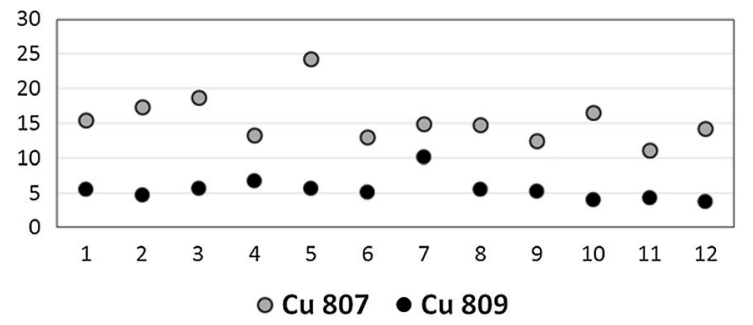

$\mathrm{Au}(\mathrm{ppm})$

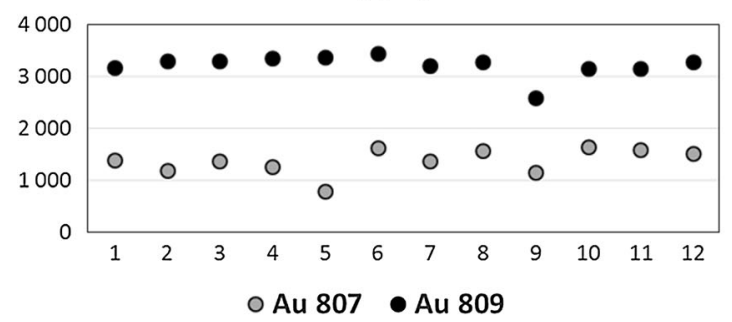

$\mathrm{Pb}(\%)$

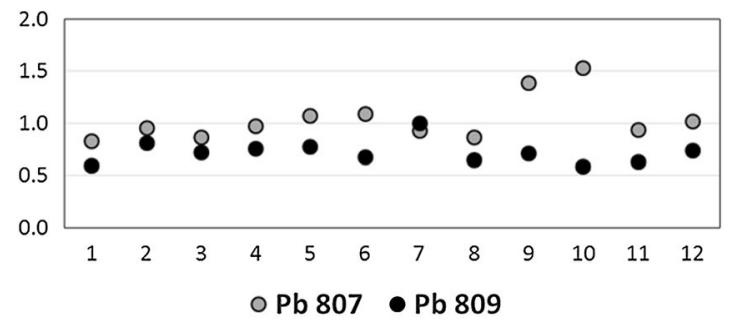

Zn (ppm)

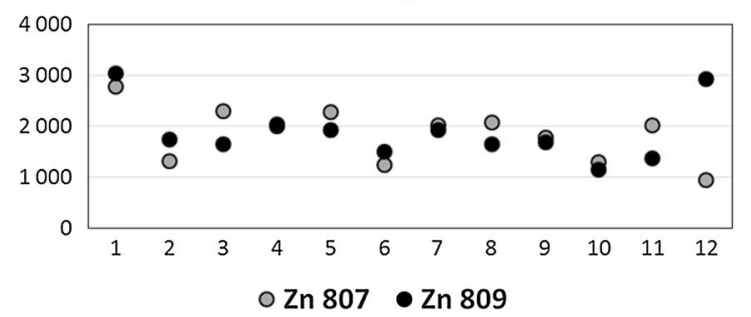

Fig. 3 Elemental concentrations (weight) of the most abundant elements ( $\mathrm{Ag}, \mathrm{Cu}, \mathrm{Pb}, \mathrm{Au}, \mathrm{Zn}$ ), measured in 12 random positions at the surface of two denarii (coin inventory numbers 807 and 809)
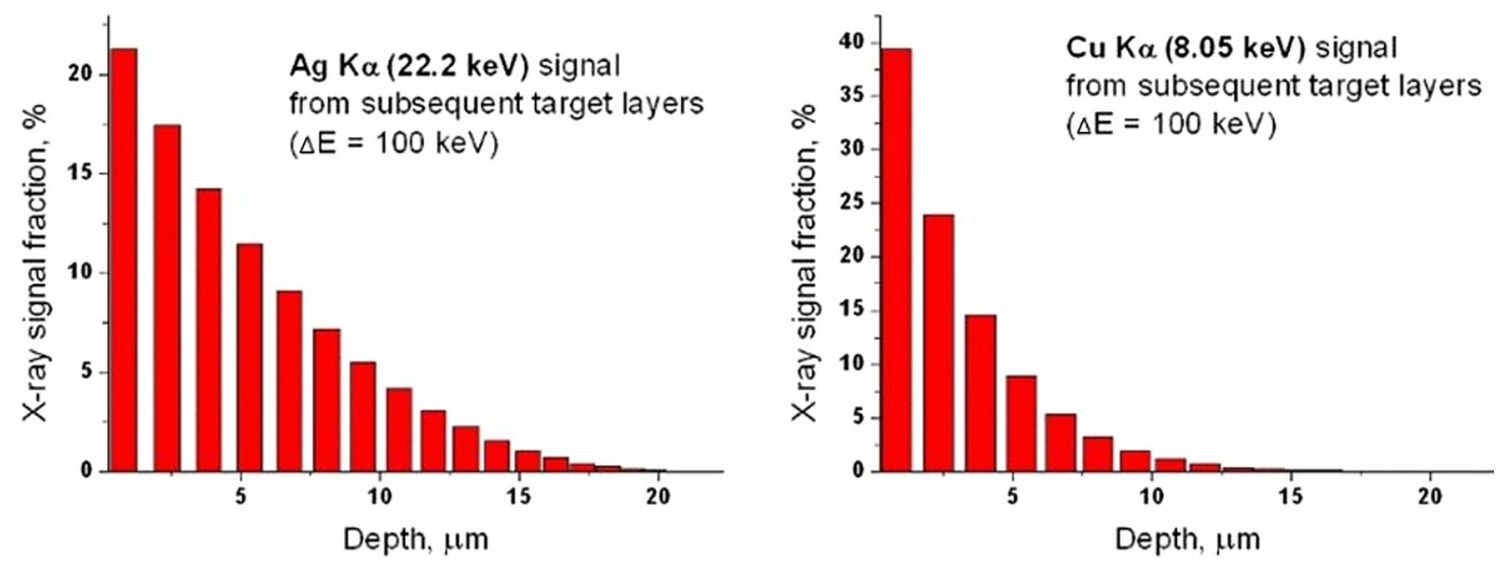

Fig. 4 Fractions of the characteristic X-ray signal for the $\mathrm{Ag}$ and $\mathrm{Cu} \mathrm{K}$-alpha lines reaching the detector, computed as a function of $\mathrm{X}$-ray origin depth

For the $\mathrm{Ag}-\mathrm{Cu}$ denarii and the applied energy of protons (2.05 MeV), the maximum depth was about $12 \mu \mathrm{m}$ for the characteristic radiation of $\mathrm{Cu}(\mathrm{K} \alpha)$ and $17 \mu \mathrm{m}$ for $\mathrm{Ag}(\mathrm{K} \alpha)$. In XRF studies these values were higher (especially the value for $\mathrm{Ag}$ line, by a factor of about 2). However, the quantification method used in this technique (comparison with $\mathrm{Ag}-\mathrm{Cu}$ standards), in case of layered structure of denarii, had even a more pronounced effect in the reliability of concentration results as compared to PIXE.

Figures 5 and 6 summarize final results for the whole collection, illustrating the dependence between $\mathrm{Ag}$ and $\mathrm{Cu}$ content, determined by XRF and PIXE. 

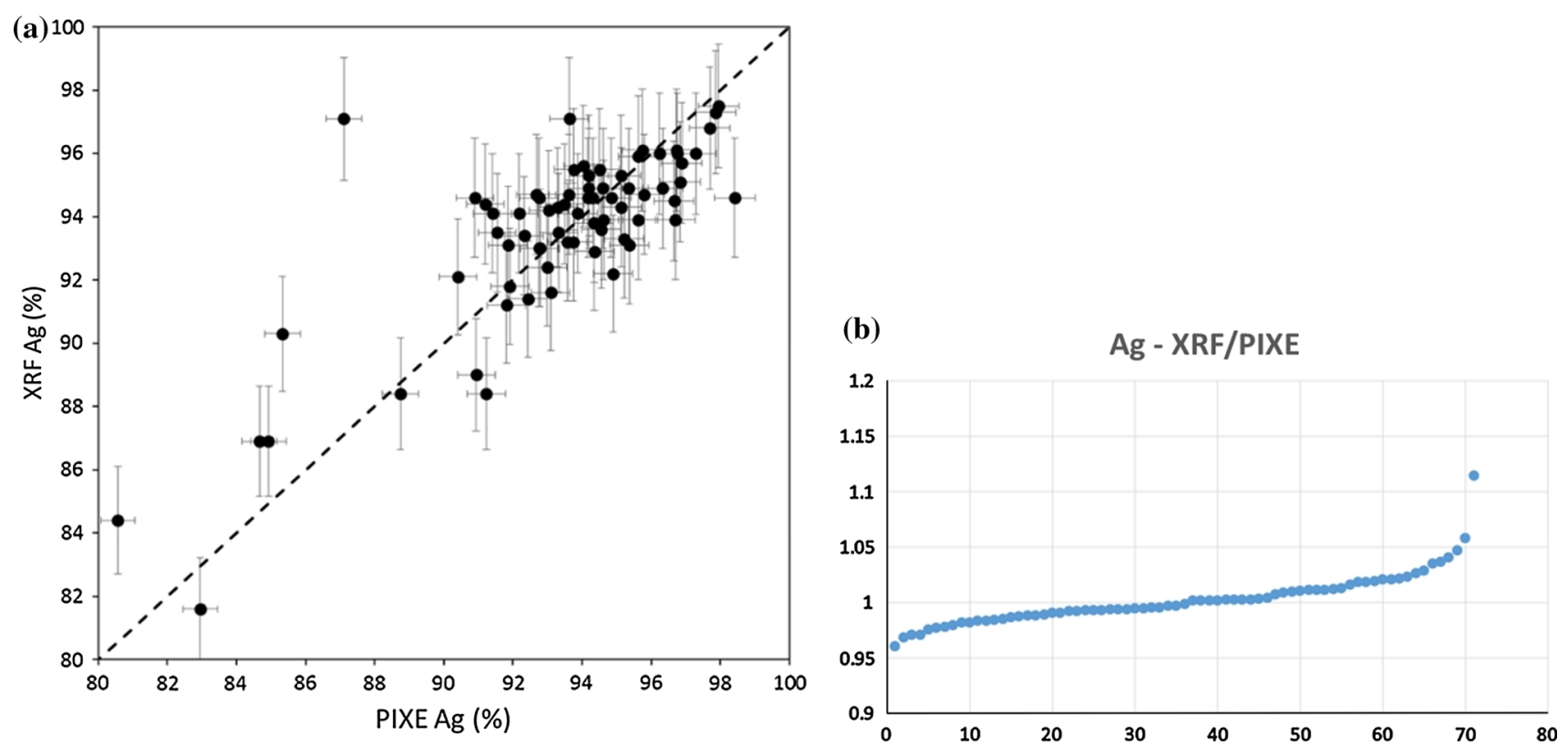

Fig. 5 Ag content-comparison of all XRF and PIXE measurements: a XY plot, $\mathbf{b}$ ordered plot: relation between XRF and PIXE results plotted against denar number
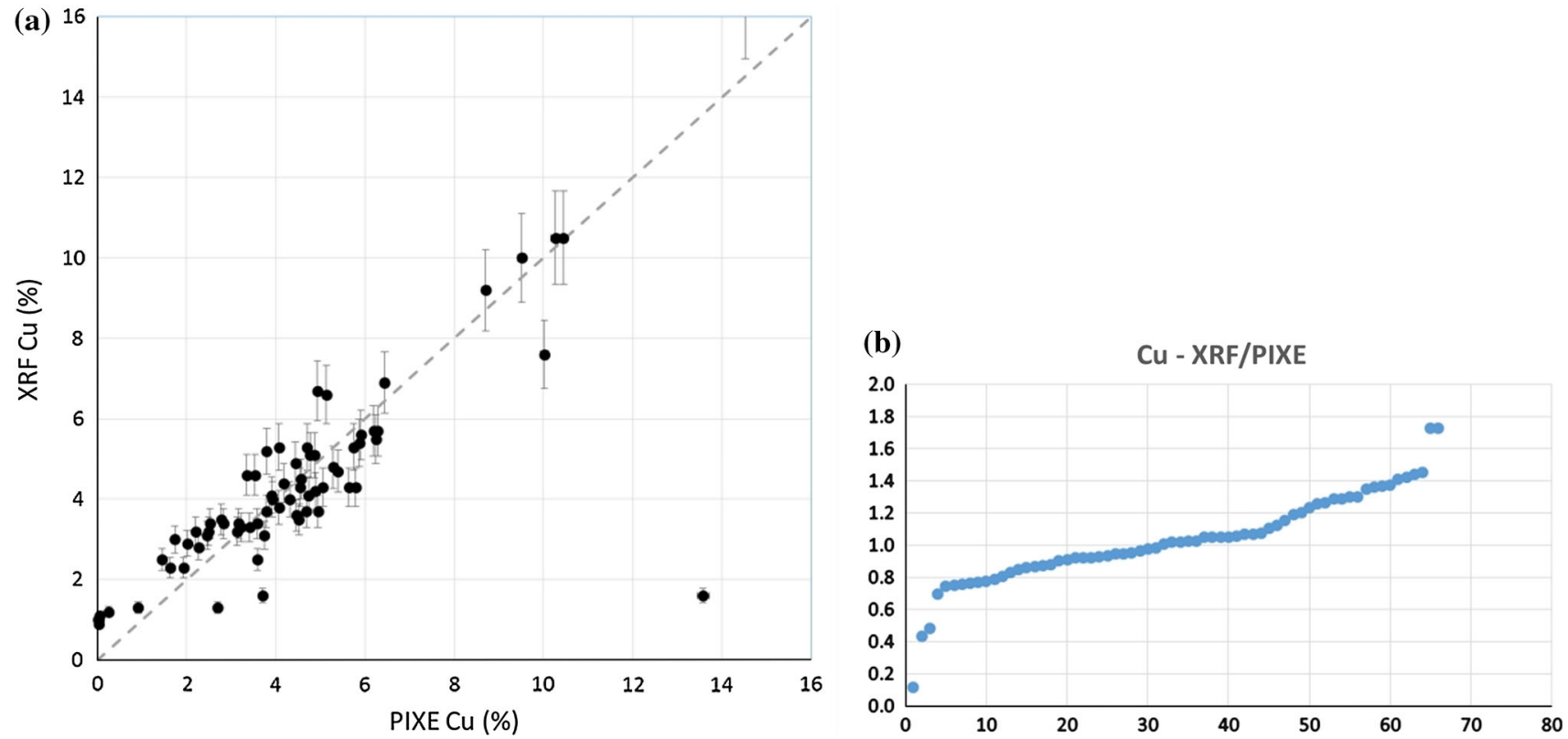

Fig. $6 \mathrm{Cu}$ content - comparison of all XRF and PIXE measurements: a XY plot, $\mathbf{b}$ ordered plot: relation between XRF and PIXE results plotted against denar number

In the case of $\mathrm{Ag}$, the obtained results show a good agreement between both experimental techniques, virtually all data are consistent and remain within a $\pm 5 \%$ range.

For $\mathrm{Cu}$, the agreement between XRF and PIXE results is worse, relative to that obtained for Ag. Not only the range of results is broader, but also many excessive points are present. In particular, few denarii with a very low $\mathrm{Cu}$ content determined by PIXE (below 1000 ppm) are characterized by a high $\mathrm{Ag}$ content in the $97-98 \%$ range and less significantly, by the relative high $\mathrm{Pb}$ content of $\sim 2 \%$. This deficit of $\mathrm{Cu}$ could be caused by corrosion processes leading to silver surface enrichment. Disturbances in the surface layer, including Ag enrichment and deposition of corrosion products, are reflected in variations registered after evaluating the measurements of $\mathrm{Ag} \mathrm{K}$ and $\mathrm{Ag} \mathrm{L}$ lines intensities. As the $\mathrm{L}$ line is more prone to 
Fig. 7 FTIR image mosaic of a Boleslaus the Brave denar with the exemplary spectra collected from two regions
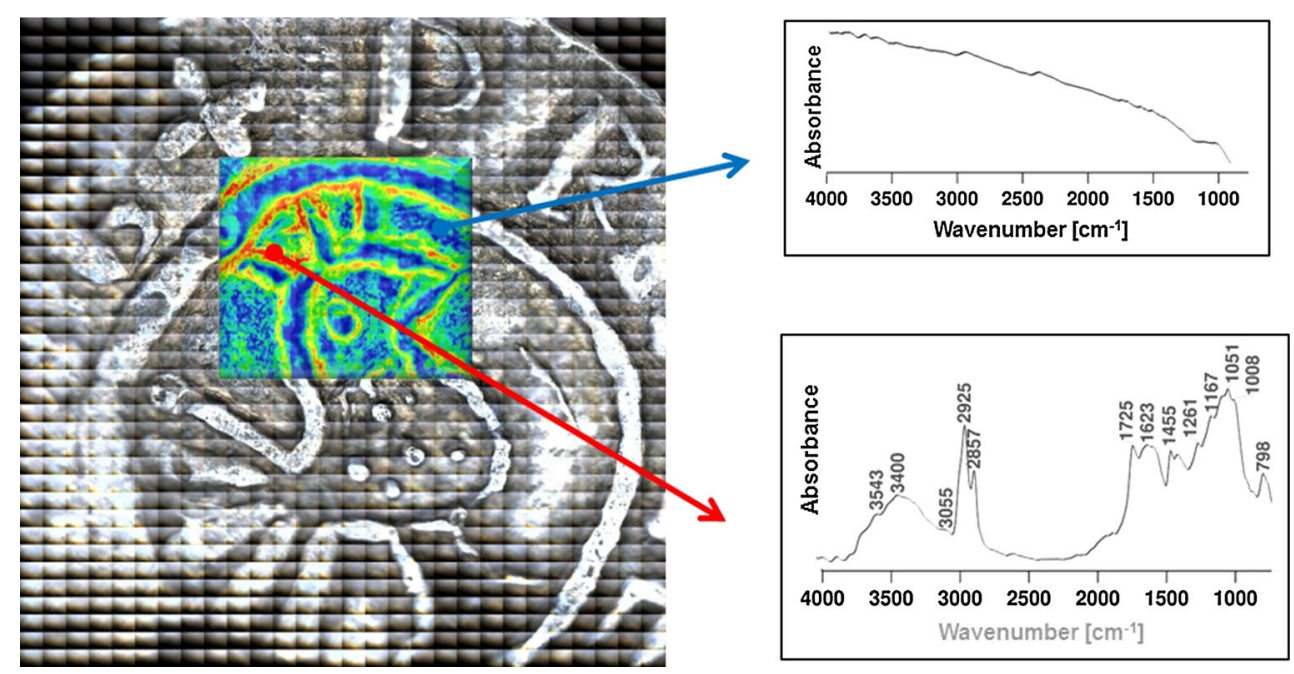

attenuation than the $\mathrm{K}$ one, the signal corresponding to the $\mathrm{L}$ line is limited to a depth of few microns, while the $\mathrm{K}$ line signal is collected from a larger depth. Therefore, excess of the $\mathrm{Ag} \mathrm{L}$ line intensity in relation to the $\mathrm{K}$ line (as compared to the homogeneous $\mathrm{Cu}-\mathrm{Ag}$ standard) suggests $\mathrm{Ag}$ enrichment (and thus $\mathrm{Cu}$ deficiency) in the near-surface layer. The opposite effect may be attributed to deposition of corrosion products in the near-surface layer.

The comparison of quantitative XRF and PIXE data has been restricted to the two major elements as the content of the next abundant element $(\mathrm{Pb})$ can be reliably quantified only by PIXE (concentration mostly below $1 \%$ ).

Scattering of the results is enhanced by the requirement that the investigated objects could not be neither cleaned nor treated. As this was indeed the case for the Cracow collection, additional FTIR measurements were carried out in order to assess the contamination layer on the denarii surface (Pięta et al. forthcoming). Figure 7 shows two examples of FTIR spectra, corresponding to two different areas on the denar surface.

The differences in the spectra are extreme. The first spectrum contains almost no valuable data. In the second one, several, well defined bands can be identified: water (3543 and $3400 \mathrm{~cm}^{-1}$ ), lipids $\left(2925,2857\right.$, and $1725 \mathrm{~cm}^{-1}$ ), phosphates $\left(1051 \mathrm{~cm}^{-1}\right)$, and silicates $\left(798 \mathrm{~cm}^{-1}\right)$.

These experimental difficulties stress the importance of a complementary and multi-technique approach for these kinds of studies especially when the Ag-enriched layer can have a thickness greater than $100 \mu \mathrm{m}$ showing the clear limitation of both techniques due to their low penetration depth. Apart of the methods described in the current paper, neutron activation analysis (NAA) has been explored as a potential technique for obtaining data delivered from the whole volume of the investigated object. Therefore, for these kinds of objects NAA may serve as a validation tool for XRF and PIXE techniques.

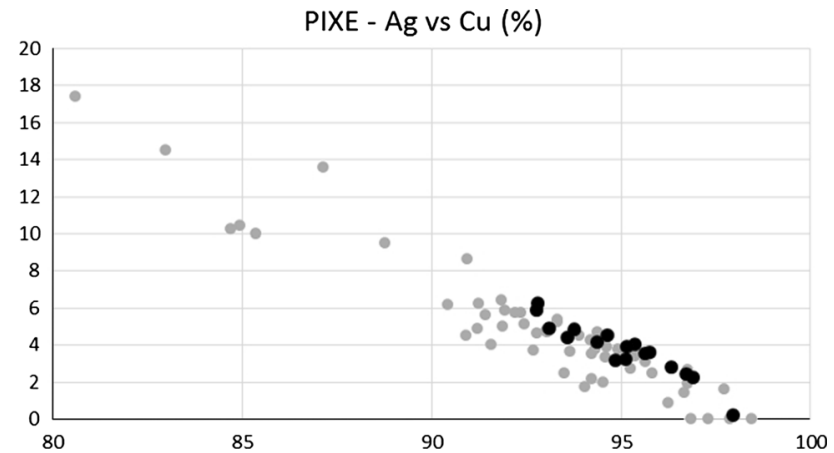

Fig. 8 Ag (horizontal) versus $\mathrm{Cu}$ content. Black points: Mieszko II denarii, grey points: Boleslaus denarii

Figures 8 and 9 show the relationship between the three most abundant elements of the denarii, namely $\mathrm{Ag}, \mathrm{Cu}$, and $\mathrm{Pb}$.

After analyzing the data the following conclusions can be drawn. The first observation is the higher elemental content definition (i.e. the narrower range of concentrations) of denarii attributed to Mieszko II (18 objects, black points, mostly later times of minting) relative to those attributed to Boleslaus (53 objects, grey points, slightly older ages). Mieszko's denarii show generally higher Ag content and are less scattered on the phase diagrams, which suggests development and mastering of extraction and minting processes over time.

Special attention was devoted to the quantification of trace elements in the measured objects, with particular emphasis placed on $\mathrm{Fe}, \mathrm{Hg}, \mathrm{Bi}, \mathrm{Zn}$, and $\mathrm{Au}$. The concentration values were considered reliable only if the relative error estimated by the GUPIX code was below $20 \%$, with the strict requirement that the calculated value is higher than the calculated detection limit plus three times the estimated error (one sigma level). Data of lesser quality were ignored. Trace elements data filtered by this 

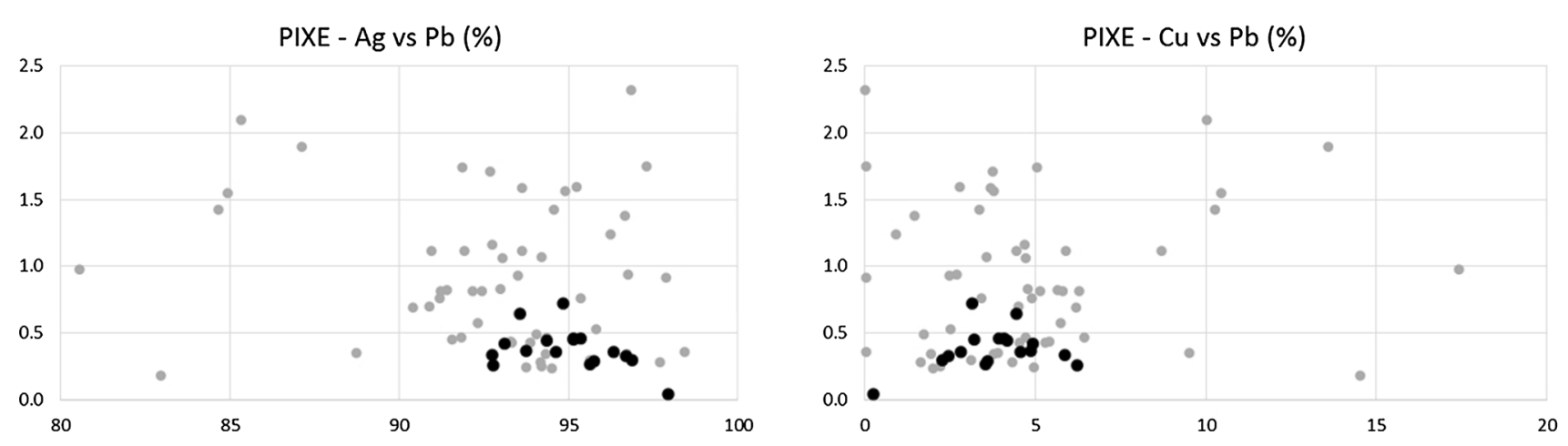

Fig. 9 Left: Ag (horizontal) versus $\mathrm{Pb}$ content; Right: $\mathrm{Cu}$ (horizontal) versus $\mathrm{Pb}$ content. Black points: Mieszko II denarii, grey points: Boleslaus denarii

procedure have been compared with qualitative results of XRF measurements [3].

Trace elements can provide information about the material source. For example, the simultaneous presence of $\mathrm{Au}, \mathrm{Zn}$, and $\mathrm{Bi}$ indicates that the source used to extract the base metal was probably the Harz mines in Germany [11]. This combination of elements has been found in several Boleslaus denarii. These three elements were reliably quantified in 11 out of 53 denarii, while in a few cases only the $\mathrm{Zn}$ value was reliable, while either the $\mathrm{Au}$ or $\mathrm{Bi}$ content was doubtful. These numbers are higher than in the XRF study (only 8 denarii with Bi traces) and the difference is due to the higher sensitivity of PIXE. It is worth to note that not a single Mieszko denar was characterized by this feature and the PIXE and XRF results of this subset did not contain reliably quantified Bi traces.

Several older denarii contained very high amounts of $\mathrm{Zn}$, from $0.6 \%$ up to even $2 \%$. It was always accompanied by a very low Ag content, usually significantly below $90 \%$ and was probably reflecting the low quality of the melted alloy.

Au traces (in the range $\sim 1000$ to $10,000 \mathrm{ppm}$ ) were found in 21 denarii with only one belonging to the Mieszko subset. This observation is in agreement with XRF results, where in 19 cases (one Mieszko denar) traces of Au were detected. However, the strong correlation between Au and $\mathrm{Ni}$, suggested by the XRF study, was not observed. There were only four cases that provide reliable results. In the whole collection, only 11 denarii showed reliably quantified Ni traces.

The presence of $\mathrm{Hg}$ is associated with a possible islamic origin [12, 13] through re-melting of Arabic denarii, abundant on Polish territory in this time. However, it is difficult to attribute this element to a single Polish ruler since good quality measurements of $\mathrm{Hg}$ (usually in the $\sim 1000 \mathrm{ppm}$ range) are present in both subsets of data (5 in Mieszko's subset and 13 for Boleslaus). These numbers are in a very good agreement with the qualitative data obtained in the XRF study (4 and 13 denarii, respectively).

Finally, Fe was reliably quantified in all investigated objects. Its concentration covered a broad range of values from few hundreds ppm up to $2 \%$. There was only one excessive case for which $5 \%$ was obtained. This denar exhibited a low $\mathrm{Cu}$ concentration below $1 \%$. However, no significant pattern was found in these data.

\section{Conclusions}

The combined use of micro-PIXE and micro-XRF spectrometry offers a promising and complementary approach for numismatic studies, especially under conditions when invasive methods such as cleaning, sectioning, and extraction of samples are not allowed. A reasonable match between results obtained with both techniques have been found.

Deposition of corrosion products at the surface of the denarii may be accountable for the variations observed due to the use of different micro-sampling locations with each of the two techniques. A preliminary assessment of the data suggests that the majority of the denarii analyzed have $\mathrm{Ag}$ surface enrichment, which is a common process observed in archaeological silver-copper alloys. A possible source of quantitative differences could be the lower penetration depth of the protons used in the PIXE analysis relative to that of the primary X-rays generated by the Rh tube used in the XRF examination. Suggested complementary techniques include NAA as a tool to gain information about the bulk material and FTIR mapping to assess the surface chemical properties.

Acknowledgements This project has been financed by the Polish Ministry of Science and Higher Education under the framework of the National Programme for the Development of the Humanities in the period 2014-2017 (Decision No. 0100/NPRH3/H12/82/2014). 
Open Access This article is distributed under the terms of the Creative Commons Attribution 4.0 International License (http://crea tivecommons.org/licenses/by/4.0/), which permits unrestricted use, distribution, and reproduction in any medium, provided you give appropriate credit to the original author(s) and the source, provide a link to the Creative Commons license, and indicate if changes were made.

\section{References}

1. Moneta polska w X/XI wieku (1967) Wiadomości Numizmatyczne XI:67-193

2. Noch einmal über die Anfänge der Münzprägung in Polen (2000) In: Kluge B, Weisser B (eds) XII. Internationaler Numismatischer Kongress Berlin 1997, Akten-Proceedings-Actes, Berlin, 978-982

3. del Hoyo-Melendez JM, Świt P, Matosz M, Woźniak M, Klisińska-Kopacz A, Bratasz $€$ (2015) Micro-XRF analysis of silver coins from medieval Poland. Nucl Instrum Methods Phys Res B 349:6

4. Zs Sándor, Tölgyesi S, Gresits I, Káplán-Juhász M (2000) Qualitative and quantitative analysis of medieval silver coins by energy dispersive X-ray fluorescence method. J Radioanal Nucl Chem 246(2):385-389

5. Lekki J, Lebed S, Paszkowski M, Kusiak M, Vogt J, Hajduk R, Polak W, Potempa W, Stachura Z, Styczeń J (2003) Age determination of monazites using the new experimental chamber of the Cracow proton microprobe. Nucl Instrum Methods Phys Res B 210:472-477
6. Kristiansson P, Borysiuk M, Arteaga-Marrero N, Elfman M, Nilsson EJC, Nilsson C, Pallon J (2010) A pre-sample charge measurement system for quantitative NMP-analysis. Nucl Instrum Methods Phys Res B 268:1727-1730

7. Campbell JL, Boyd NI, Grassi N, Bonnick P, Maxwell JA (2010) The Guelph PIXE software package IV. Nucl Instrum Methods Phys Res B 268:3356-3363

8. Beck L, Bosonnet S, Réveillon S, Eliot D, Pilon F (2004) Silver surface enrichment of silver-copper alloys: a limitation for the analysis of ancient silver denarii by surface techniques. Nucl Instrum Methods Phys Res B 226:153-162

9. Borges R, Alves L, Silva RJC, Araújo MF, Candeias A, Corregidor V, Valério P, Barrulas P (2017) Investigation of surface silver enrichment in ancient high silver alloys by PIXE, EDXRF, LA-ICP-MS and SEM-EDS. Microchem J 131:103-111

10. Ziegler JF (2013) SRIM - The stopping and range of ions in matter. www.srim.org

11. Młodecka H, Chabrzyk P (2010) XRF analysis of denarii of Boleslaus the Brave and his son Mieszko Bolesławowic in light of selected denarii from the turn of the 10th century. Biuletyn Numizmatyczny 3:171-178

12. Al-Kofahi MM, Al-Tarawneh KF (2000) Analysis of Ayyubid and Mamluk dirhams using X-ray fluorescence spectrometry. X-Ray Spectrom 29:39-47

13. Buko A (2007) "Tribal" societies and the rise of early medieval trade: archaeological evidence from Polish territories (eight-tenth centuries). In: Henning J (ed) Post-Roman towns, trade and settlement in Europe and Byzantium: the heirs of the Roman West. Walter de Gruyter, Berlin, pp 431-450 